over the surface in order to insure that it is completely impervious. Enough sand or screenings are usually added to the surface to take up any excess bitumen.

Largely because of its higher first cost, due to the additional amount of labor required, the mixing method is not used so generally in this country. The stone for the second course is mixed with the bitumen befor placing it on the road. So long as each stone is uniformly coated with the bitumen, the mixing may be done either by hand or by machine. The advocates of this method claim that a stronger and more uniformly bonded road surface is secured than can be gotten by the penetration method. Both of these methods seem able to withstand quite heavy automobile traffic. But where a heavy mixed traffic is encountered, neither method can be said to be anything like ideal.

Brick roads are coming into favor in many section where a good paving brick can be produced at a low cost. A good paving brick or block, when laid on an unyielding foundation, is able to resist very hection mixed traffic without serious injury. In such section
as Ohio and Pennsylvania, brick should find considerable use as a local material, especially in the construction of trunk line roads engaged in carrying heav mixed traffic.

From the above it can readily be seen how largely the solution of road problems confronting any com munity depends on local conditions. What is a solution in one place may be a mistake in another, and what is advisable in one locality it may be folly to use in another. The Government, in recognition the diversity of the road problems and the need of skilled assistance in their solution, has established the Office of Public Roads in the Department of Agriculture. Aside from roads constructed in island possessions and in National parks, the Government makes no direct appropriation for road building, except a small annual appropriation for experimental work. Through the investigations and researches carried on by the Office of Public Roads and its corps of trained experts and engineers, it has done much to reduce the cost of road improvements and to prevent loss through the use of improper methods and unsuitable materials. The Government does not in any way compete with individuals or companies, but takes up those lines which would otherwise remain undone and thus cause great loss to the country at large.

\title{
The Scientific Aspects of Bell-Making
}

\author{
A Foundryman Who Must be a Metallurgist as well as a Musician
}

By H. J. Shepstone

THIE art of bell-making is one of the most ancient 1 and one of the most modern in the world. From the first dawn of civilization men have evoked sounds from crude instruments that in principle, if not in shape, bore some resemblance to a bell. To-day the best brains are being picked everywhere to produce bells that are at once durable, artistic, and melodious. Bells are made in a score of forms and sizes, and they are turned to a thousand uses. Many of the most thrilling events in history have sprung from the vibrations of a bell. All through the centuries the pealing of a "Great Tom," or a "Santa Maria," has called men to prayer, summoned them to battle, and warned them of the approach of storm and flood and fire. As early as the year 680, church bells were imported into Eng land from Italy. Now the process is reversed. Bells are manufactured in England and exported to the ends of the earth.

Indeed, the oldest industries in Great Britain to-day are the bell-foundries. There is one in Whitechapel, in London, that was founded 350 years ago and it is by no means the oldest. There are many whose existence can be traced back for a couple of centuries and more. Our photographs, however, depict the method of bell-making as carried out in one of the more recent establishments, namely, that of Gillett and Johnson, of Croydon, England, where bells have been turned out for over half a century in large quantities for all parts of the world. The firm is famous for the many big of the world. The firm is famous for the
bells it has cast and for their beautiful tone.

The metal from which the bell of to-day is made is usually composed of sixteen parts of copper to five of tin. But this standard is not uniform, and it is liable to modifications. Sometimes when a founder in olden days had cast a bell away from his manufactory, he was driven by time or circumstances, to put in too much or too little of one of the ingredients. The result was always more or less unsatisfactory. Then again, tin melts at 440 degrees, and it requires 1,995 degrees for the same operation in copper. Thus the former metal, to some extent, evaporates in the furnace, and has to be replenished a little. In the case of hand-bells, the proportion of copper is increased. This is because the sides, being thin, the normal ratio of tin would render sides, being thin, the normal ratio of tin would render
them liable to crack. Old copper makes the best metal and most of the tin used by the larger bell-founders comes from Australia.

The first step, of course, is the building of the mold. Indeed, it is the most vital stage in the evolution of a bell. A blunder here might mean so dismal a failure that the ordeal of casting would have to be repeated, or even an explosion, in which men and buildings might be blown to fragments. At the bottom of the deep pit under the mouth of the furnace, the workmen, with a pile of bricks, build up a structure called the "core." This forms the shape and dimensions of the inner side of the bell. The core is then coated with loam, smoothed with a delicately adjusted crook, or template, worked on a pivot, and then thoroughly dried. An iron hood is requisitioned to form the outer side of the future "Great Peter" or "Ave Maria." The inner part of the case is spread with loam and carefully smoothed and molded by the crook. The hood is then hoisted over the core, and adjusted to it with the utmost exactness. The distance between them represents the space to be filled by the metal when it rushes from the furnace. It is obvious that if the two sections of the mold do not precisely correspond with each other, the bell cannot be uniform in its shape and its thickness. Carefully smoothed channels lead from the orifice of the furnace to the top of the pit. The flow of metal can easily be regulated into the mold or diverted from it.

When the bell is cast and trimmed it is transferred to the tuning-shop, where by means of modern machines, specially designed for the purpose, metal is pared off from the inside of the bell according to the need. Perhaps the greatest revolution in the bell world of modern times has been with regard to the tuning. Canon Simpson, an English clergyman, was the first man to point out to the musical public that bells were rarely, if ever, in tune, but that this state of things could be remedied if certain facts were borne in mind. Briefly, the facts are these: That a bell, to be properly in tune with others, must first be properly in tune with itself, namely, it must have at least five tones at correct intervals to one another, so as to form a perfect musical chord. These tones or harmonics, as the are called, are the hum-note, fundamental, and nominal, also the third and fifth to the fundamental (o strike note). Putting the first three named in musica notation, with a $\mathrm{C}$ bell for example, we get-

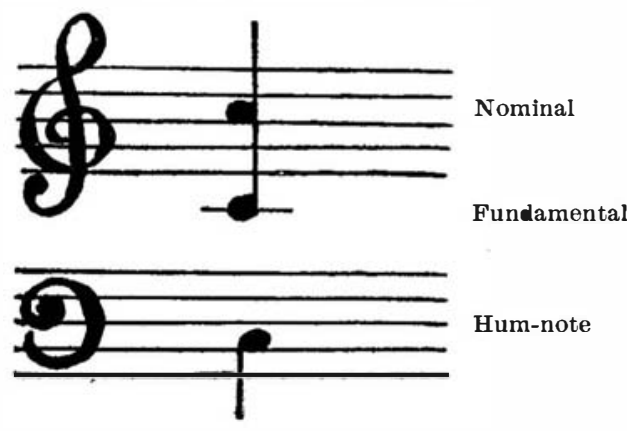

thus producing three C's in octave.

Small bells, curiously enough, were always the bellfounders' trial, and the smaller they were, the worse were their tone and tune; but with the complete mastery of the harmonics all these difficulties passed away, and no matter how small the dimensions, bells can be made to sound as pure and sweet in tone and accurat in tune as any other musical instrument. Naturally the casting of these hand-bells is child's play compared to fashioning a giant of half a ton in weight. Wit their modern appliances it is easy for the workmen to bale out the hot metal and pour it into the little molds. Then the production of the accessories is a very im portant branch of the work of a modern bell-foundry. When it is remembered that ringers are sometimes fondling their ropes for more than four hours at time, it is clear how necessary it is that a peal should swing smoothly and accurately. The sockets in whic the bars that support the bell are inserted are made of gun-metal, and are as smooth as glass. Formerly the beams of a belfry were invariably of oak or othe wood. Now timber is yielding to metal. Out of eight frames that were in the course of construction in the foundry under notice only one set was made of oak. All the others were fashioned in iron. The wheels, which swing to and fro as the ropes are pulled, are oaken, and display the most skillful workmanship. The ropes are all stretched across a beam, with a heav weight at each end of them, until by the strain they become as hard and as supple as strips of steel.

Eight bells generally form a peal in a church tower. The first peal of bells to be erected, namely, a collection of bells tuned in harmony together, was that built in Crayland Abbey, in Lincolnshire, in 870. It was in the seventeenth century that real "change" ringing came into vogue and became exceedingly popular. To-day it has certainly reached a very high state of perfection. It may be of interest here to note that whereas a peal of five bells will allow but 720 changes, from a peal of twelve bells 479,001,600 changes can be rung! The heaviest ringing peal of bells in the world is that in the South Tower of Exeter Cathedral. There are te bells in the peal, the smallest having a diameter of
2 feet $81 / 2$ inches, and a weight of 806 pounds, the largest boasting of a diameter of 6 feet and a weight of 8,112 pounds, or 3.6 English tons. Then there is probably no other article as good as new after half a century of wear as a church bell, for even if it becomes cracked it is still worth two-thirds of its original value.

\section{Work of the Bureau of Printing and Engraving}

Probably few of the users of postage stamps and Psenders of greenbacks realize that these two articles are the product of one of the biggest factories belonging to a national government: viz., the United States Bureau of Printing and Engraving, at Washington. The report of Director Ralph for the fiscal year 1911, just published, contains some impressive facts and figures.

The amazing number of ten billion postage stamps were printed here last year-to be exact, 9,773,424,200 . The output of notes, certificates and bonds was about 67,000,000 sheets; of national bank notes, $12,000,000$ sheets; of internal revenue stamps, $84,000,000$ sheets; of customs stamps, 153,000 sheets; of checks, drafts and miscellaneous, 2,266,581 sheets. In all, $262,806,113$ sheets of the various government issues were printed.

The enormous output of paper money is explained by the fact that its average life is only between two and three years. Americans are averse to the use of coin. Thus nearly the whole of our gold coinage goes into the Treasury, where is lies inert, while the paper money issued against it circulates. The Treasury now holds more than $\$ 1,200,000,000$ in gold-such an accumulation, it is said, as has never before been known.

\section{Cipher Wireless Telegraphy}

THE use of secret writing in wireless telegraphy is bound to prove especially advantageous as accordwith the present state of affairs everybody acquainted less telegram at short distance even with the ear, unassisted by any receiving apparatus.

If the order of letters in the alphabet be changed in any way, placing the alphabet in its right order above this row of letters and replacing each letter of a document by the corresponding letter of the permutated alphabet, a ciphered document, viz., a document in secret writing will be obtained. Now it is a well-known fact that none of the secret alphabets so far suggested was able to resist the art of deciphering. As in fact each letter occurs with a given frequency in each language (the German e for instance 90 times, the $n 60$ times, the s 50 times, the $t 40$ times in a total of 600 letters), it is merely required to figure the numbers of equal letters in order at once to know which are the letters e, n, s, t, etc. Any less frequent letters are simply guessed, after ascertaining the identity of the rest.

Prof. Zehnder's secret writing readily adapts itself to the typewriter, any chance of deciphering (in the absence of a key) being removed by using for each line or even each word another permutatèd alphabet. In this case any attempt at deciphering by calculation will be hopeless indeed as each letter occurs with about equal frequency. A typewriter allowing the alphabet to be exchanged for each line or even earh word could readily be constructed on the type-roller system.

This scheme suggested by Zehnder as far back as thirty years ag - for the secret political correspondence of Abyssinia had never been made public until its present contemplated application to wireless telegraphy. 